Témoigner Témoigner. Entre histoire et mémoire

Getuigen Revue pluridisciplinaire de la Fondation Auschwitz

$122 \mid 2016$

Révisionisme et négationisme

\title{
Bevrijding! Belgen in de Duitse kampen
}

Des témoins muets? Les photos, un matériau d'exposition historique complexe

Karla Vanraepenbusch et Jan Julia Zurné

\section{Q OpenEdition}

\section{Journals}

Édition électronique

URL : https://journals.openedition.org/temoigner/4059

DOI : 10.4000/temoigner.4059

ISSN : 2506-6390

Éditeur :

Éditions du Centre d'études et de documentation Mémoire d'Auschwitz, Éditions Kimé

Édition imprimée

Date de publication : 2 mai 2016

Pagination : 8-12

ISSN : 2031-4183

Référence électronique

Karla Vanraepenbusch en Jan Julia Zurné, «Bevrijding! Belgen in de Duitse kampen», Témoigner. Entre histoire et mémoire [Online], 122 | 2016, Online op 30 septembre 2021, geraadpleegd op 04 janvier 2022. URL: http://journals.openedition.org/temoigner/4059 ; DOI: https://doi.org/10.4000/temoigner. 4059 


\title{
BEVRIJDING! BELGEN IN DE DUITSE KAMPEN
}

\author{
TENTOONSTELLING Stille getuigen? Over de complexiteit van foto's als historisch \\ tentoonstellingsmateriaal.
}

V orige lente was het zeventig jaar geleden dat de concentratiekampen werden bevrijd. Foto's van die bevrijdingen gingen de wereld rond en verwierven in de collectieve herinnering al snel een iconische status. De publicatie van de foto's zorgde er immers voor dat de kampen uitgroeiden tot het symbool voor de Holocaust en met uitbreiding voor alle door de nazi's begane misdaden. De dubbeltentoonstelling Bevrijding! Belgen in de Duitse kampen toont aan dat er nog steeds onbekende collecties en verhalen zijn. Beide tentoonstellingen, de een in Kazerne Dossin, de ander in Fort Breendonk, hebben drie gemeenschappelijke uitgangspunten. Allereerst vertellen ze een verhaal dat zich afspeelt in de lente van 1945 tijdens de bevrijding van de Duitse concentratiekampen. Ten tweede focussen ze daarbij op de groep van Belgische politieke gevangenen. Ten derde valoriseren de tentoonstellingen twee fotocollecties, bewaard in het Studiecentrum Oorlog en Maatschappij, die nooit eerder gepubliceerd noch tentoongesteld werden.

Omdat beide tentoonstellingen erg verschillend zijn wat ruimte, budget en museografie betreft, bespreken we in dit artikel wat ze gemeenschappelijk hebben: de foto's van de bevrijding. Het lijkt alsof dergelijke beelden het verhaal vertellen van een historische gebeurtenis, maar ze doen tegelijkertijd meer en minder dan dat. Enerzijds tonen ze slechts fragmenten van een verhaal. Soms laten ze de essentie zelfs helemaal niet zien, zoals het geval is met de foto's die symbool staan voor de Holocaust, maar die vrijwel nooit de uitroeiing zelf tonen. Anderzijds laten ze niet enkel de historische gebeurtenis zien, maar ook en vooral het verhaal dat de fotograaf koos erover te vertellen. Wanneer foto's tentoongesteld worden in een museum, dan illustreren ze boven- dien ook het discours van de tentoonstellingsmakers (Struk 2004, 3-15).

\section{DE FOTO'S:}

\section{EEN VREEMDSOORTIGE KAMPWERKELIJKHEID}

In de Kazerne Dossin is Buchenwald het uitgangspunt. Walter Ganshof van der Meersch, magistraat en hoofd van het Hoog Commissariaat voor 's Rijksveiligheid, reist in het voorjaarvan 1945 voor onderzoek naar oorlogsmisdaden door Duitsland. Zijn broer FrançoisLouis neemt onderweg foto's, onder andere van het bezoek aan het bevrijde concentratiekamp Buchenwald en de repatriëring van de meer dan zeshonderd Belgische oud-gevangenen. De tentoonstelling in Fort Breendonk laat de bezoeker in de sporen treden van oorlogscorrespondent Paul M.G. Lévy. In 1945 volgt hij de geallieerde troepen door Duitsland en zoekt Belgische politieke gevangenen op in de zopas bevrijde concentratiekampen. Zijn reisgenoot Raphaël Algoet doet dienst als fotograaf.

Algoet en Ganshof hebben met hun beeldmateriaal een unieke bron nagelaten voor historici die willen weten hoe de concentratiekampen er in de eerste weken na de bevrijding uitzagen. De meeste overlevenden zijn op dat moment nog aanwezig, waardoor voor korte tijd een vreemdsoortige kampwerkelijkheid blijft voortbestaan, zij het zonder bewakers. Algoet en Ganshof leggen vast hoe ex-gevangenen hun bevrijders en andere bezoekers tonen welke martelmethoden werden gebruikt en hoe ze bloemenkransen plaatsen ter herdenking van gestorven kameraden.

Er zijn echter allerlei aspecten van het tijdsvacuüm tussen gevangenschap en vrijheid die onzichtbaar blijven. De camera kon wel de opgestapelde lichamen vastleggen, maar de foto's vertellen ons 


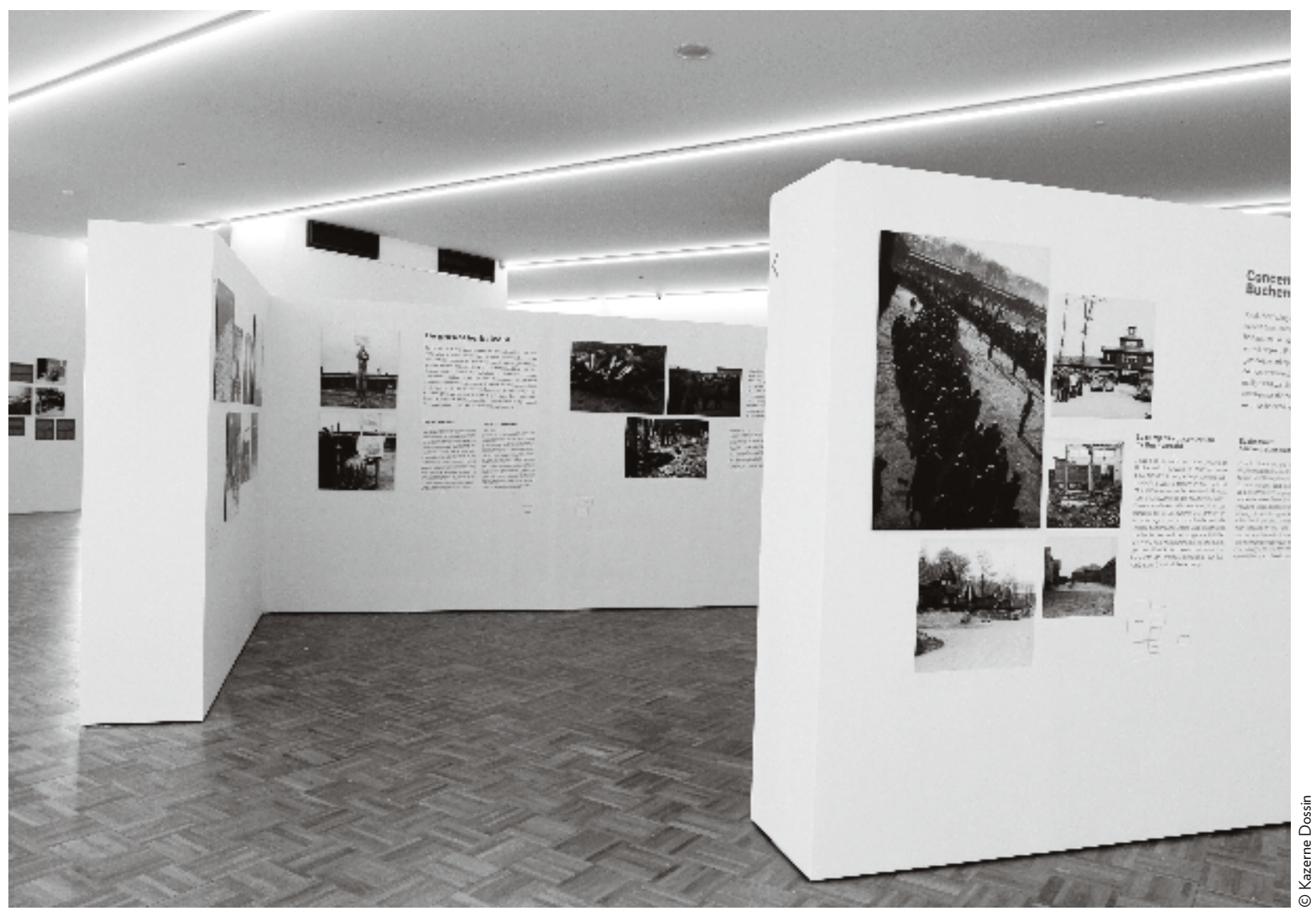

_ Overzichtsbeeld tentoonstelling Kazerne Dossin.

weinig over de duizenden gevangenen die na de bevrijding nog dagelijks stierven. Ook de ondraaglijke stank op de kampterreinen blijft verborgen. Op sommige afbeeldingen zijn juichende gevangenen te zien, maar de wanhoop die velen van hen beleefden als gevolg van totale uitputting en angst voor de toekomst, is moeilijker in beelden te vatten (Stone 2015, 87-97). Hetzelfde geldt voor de ervaringen van de bevrijders. Voor veel militairen was de confrontatie met de gruwelijke werkelijkheid van de concentratiekampen traumatisch, ondanks hun eerdere oorlogsondervindingen. Ook voor Algoet, Lévy en de broers Ganshof moeten hun bezoeken aan de concentratiekampen choquerend en zeer indrukwekkend zijn geweest. Helaas kennen we, behalve enkele korte opmerkingen van Lévy, hun reactie niet. De fotografe Margaret Bourke-White, die voor het Amerikaanse leger het pas bevrijde Buchenwald documenteerde, omschreef later hoe ze tijdens haar bezoek in een verdoofde toestand verkeerde. Het was pas toe ze de negatieven ontwikkelde dat de afgebeelde gruwelen tot haar doordrongen. Tijdens het fotograferen vormde de camera een barrière tussen haarzelf en de verschrikkingen (Struk 2004, 124).

Ook op het grote publiek maakten foto's van de bevrijde concentratiekampen veel indruk en konden ze zelfs, zoals Susan Sontag haar eigen ervaring omschrijft, een (negatieve) openbaring zijn (Sontag 1977, 31). Afbeeldingen vergelijkbaar met die van Ganshof en Algoet vormden in 1945 en daarna voor de wereld bewijsmateriaal van de nazimisdaden. Gruwelijke verhalen die eerder soms werden afgedaan als propaganda, bleken waar te zijn. De afbeeldingen vormden 


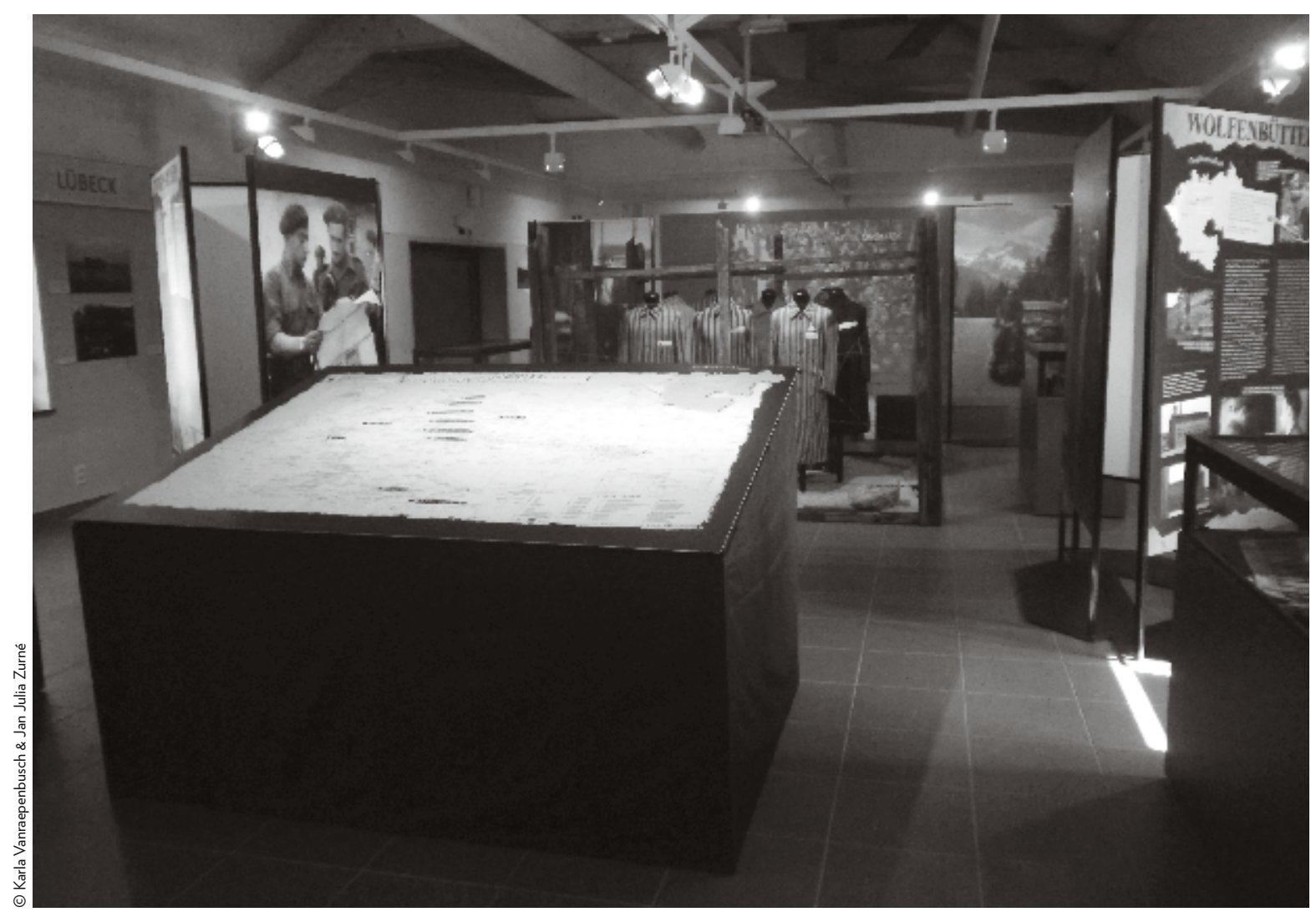

_ Overzichtsbeeld tentoonstelling Fort Breendonk.

•• een 'onomstotelijk bewijs' (Sontag 1977, 14). Het in de pers verschenen werk van Britse en Amerikaanse fotografen had inderdaad deze functie en werd vergezeld van titels als 'Seeing is believing' (Struk 2004, 125126). De foto's van Algoet en Ganshof zijn dus, behalve interessant bronnenmateriaal, ook bewijsmateriaal in niet-juridische zin. Tot nu hebben ze die rol echter niet voor het grote publiek vervuld omdat ze nooit in de pers zijn verschenen. Het waren stille getuigen.

\section{DE TENTOONSTELLINGEN:}

\section{PERSOONLIJKE VERHALEN}

In musea die tegelijkertijd memorialen zijn, functioneren beelden anders dan in reguliere tentoonstellingsruimtes. Ze doen er niet louter dienst als visuele documenten, maar getuigen ook van een moeilijk verleden. De vele foto's van slachtoffers in memori- aal-musea benadrukken het collectieve aspect van de gruweldaad (Edwards \& Lien 2014, 12), en zorgen ervoor dat de groep slachtoffers zichtbaarheid en erkenning verwerft in het publieke bewustzijn (Williams 2012, 99). Dat is niet anders voor de dubbeltentoonstelling Bevrijding! Belgen in de Duitse kampen. De groep slachtoffers waar de curatoren zichtbaarheid aan geven en waarvoor ze indirect erkenning vragen, wordt gevormd door de Belgische politieke gevangenen in de Duitse concentratiekampen.

De curatoren van Bevrijding! kozen er bewust voor om weinig gruwelbeelden te tonen. Slechts enkele foto's tonen opeengestapelde lijken en foltertuigen. De meeste laten vooral de bevrijding, de repatriëring en de vreugde van de gevangenen zien. Het is immers niet duidelijk of gruwelijke beelden, die de pijn tentoonsprei- 
den van anderen, een moraliserende invloed hebben op het museumpubliek of juist onverschilligheid oproepen (Williams 2012,111). Bovendien kan men betwijfelen of het hedendaags museumpubliek tentoonstellingen wil bezoeken die uitsluitend uit gruwelbeelden bestaan, en die de gruweldaden van massadeportatie en gevangenschap in een concentratiekamp enkel nog minder begrijpelijk maken (Struk 2004, 194).

In Kazerne Dossin kozen de curatoren voor een benadering die persoonlijke verhalen centraal plaatst. Het team deed dat in de eerste plaats, zoals de tentoonstellingsteksten aangeven, om een identiteit terug te geven aan de gevangenen die in Buchenwald overleefden 'zonder naam, zonder verleden of toekomst'. Een van de tentoongestelde foto's getuigt zo letterlijk van het proces waarbij de nazi's gevangenen ontmenselijken door hen te herleiden tot nummers. We zien een groep gevangenen die allen hun getatoeeerd kampnummer tonen. De meeste foto's dragen zelf nog eens bij aan de ontmenselijking, want ze tonen de gevangenen als een collectief waarbij elk individu hetzelfde streepjespak draagt en hetzelfde gekortwiekte kapsel heeft (Struk 2004, 198). De curatoren hebben dit probleem verholpen door een zestigtal personen op de foto's te identificeren, en in korte tekstjes hun levensverhaal samen te vatten. In het Verzetsmuseum in Amsterdam liep in 2015 de tentoonstelling Geen nummers maar namen over Nederlandse politieke gevangenen in Dachau, die dezelfde benadering volgde.

De tentoonstelling in het Fort van Breendonk brengt daarnaast een persoonlijk verhaal, dat van $\bullet \bullet$

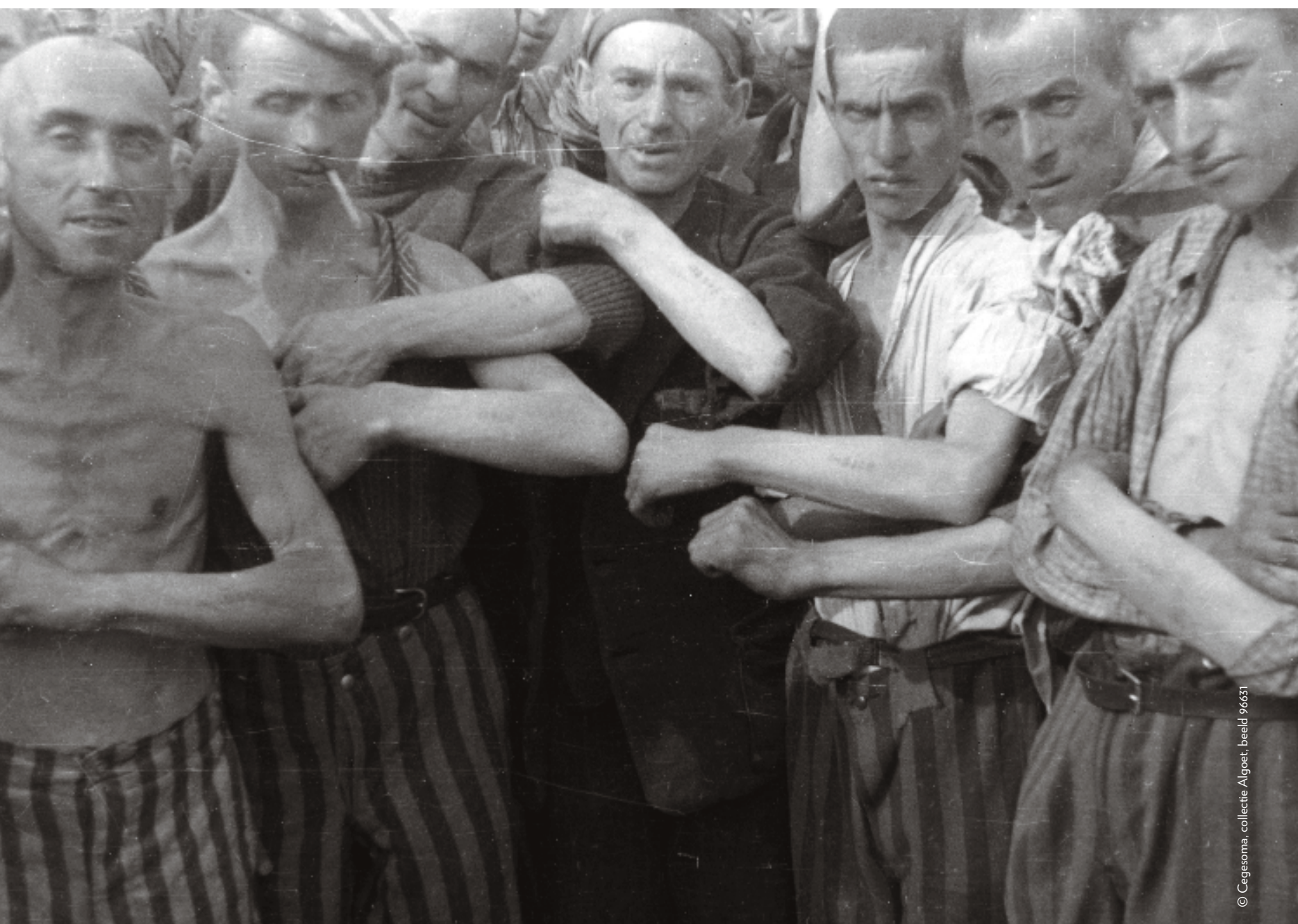


$\bullet \bullet$ oorlogscorrespondent Paul Lévy. Hij is een kleurrijk personage: oud-gevangene van Breendonk, na zijn vrijlating gevlucht naar Londen en daar in dienst van de regering in ballingschap, na de bevrijding conservator en voorzitter van het memoriaal in Breendonk. Het tentoonstellingsparcours volgt Lévy's naoorlogse reis door Duitsland. De makers besteden ruime aandacht aan de plaatsen die hij aandoet. Elk tekstpaneel beschrijft de situatie in en bevrijding van een bepaald kamp, geïllustreerd met foto's van de kampinfrastructuur en de gevangenen. Zo ontstaat er een schakering van verhalen over de organisatie en omstandigheden in verschillende Duitse concentratie- en werkkampen. Bijzondere aandacht gaat naar Dachau, aangezien Lévy daar als eerste aanwezig was, zelfs nog voor de aankomst van de Amerikaanse bevrijders. Een handvol foto's waarop de reizende Lévy staat afgebeeld werden uitvergroot en gekadreerd, en nemen een centrale plaats in de tentoonstelling in. De bezoeker volgt zo in feite twee sporen, die elkaar op bepaalde momenten kruisen.

Beide tentoonstellingen slagen er, ondanks de bijzondere persoonlijke verhalen die ze vertellen, niet helemaal in om de gefotografeerde personen echt tot leven te wekken. De curatoren van de tentoonstelling in Kazerne Dossin belichten het verhaal van zestig van de zeshonderd Belgische politieke gevangenen die zich tijdens de bevrijding in Buchenwald bevonden. Dat zijn er eigenlijk toch nog te veel om de bezoeker toe te laten gezichten te herkennen en individuele verhalen te onthouden. In het Fort van Breendonk leren we een personage kennen dat larger than life is, maar we komen amper te weten wat hij dacht over de gruwel die hij tijdens zijn reis zag.

\section{TE VEEL VERHALEN?}

De voor de dubbeltentoonstelling geselecteerde foto's van Algoet en Ganshof zijn stille getuigen van de bijzondere periode kort na de bevrijding van de kampen in de lente van 1945. Nu ze eindelijk ter beschikking staan van een ruimer publiek, blijken ze echter bijzonder complex materiaal op te leveren. Foto's tonen immers niet alles: als medium schieten ze tekort om te vertellen over wat voor en na de momentopname is gebeurd, en wat de personen voor en achter de camera voelden en beleefden. Ze zijn ook nooit neutraal: noch op het moment van opname, noch in hun status als tentoonstellingsobject. Het thema van de bevrijding van de concentratiekampen is dan weer zodanig rijk dat het moeilijk is een duidelijke focus te kiezen. Er zijn simpelweg te veel verhalen om te vertellen. I

\section{Karla Vanraepenbusch (UCL - Cegesoma) Jan Julia Zurné (UGent - Cegesoma)}

\footnotetext{
Bibliografie

Elizabeth Edwards \& Sigrid Lien (red.), Uncertain Images: Museums and the Work of Photographs, Farnham/Burlington: Ashgate, 2014.

$\rightarrow$ Susan Sontag, Over fotografie, Amsterdam: De Bezige Bij, 2008 (oorspronkelijk: On Photography, New York: Farrar, Straus and Giroux, 1977).

$\rightarrow$ Dan Stone, The Liberation of the Camps. The End of the Holocaust and Its Aftermath, New Haven/London: Yale University Press, 2015.

$\rightarrow$ Janina Struk, Photographing the Holocaust: Interpreting the Evidence, London: I.B. Tauris, 2004.

$\rightarrow$ Paul Williams, 'The Memorial Museum Identity Complex. Victimhood, Culpability and Responsibility', in Bettina M. Carbonell, Museum Studies: An Anthology of Contexts, Malden/Oxford: Wiley-Blackwell, 2012, pp. 97-115.
}

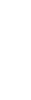

